San Jose State University

SJSU ScholarWorks

Master's Theses

Master's Theses and Graduate Research

Spring 2016

\title{
Variation in adrenal and thyroid hormones with life-history stage in juvenile northern elephant seals (Mirounga angustirostris)
}

Jennifer Jelincic

San Jose State University

Follow this and additional works at: https://scholarworks.sjsu.edu/etd_theses

\section{Recommended Citation}

Jelincic, Jennifer, "Variation in adrenal and thyroid hormones with life-history stage in juvenile northern elephant seals (Mirounga angustirostris)" (2016). Master's Theses. 4690.

DOI: https://doi.org/10.31979/etd.vd6t-92rr

https://scholarworks.sjsu.edu/etd_theses/4690

This Thesis is brought to you for free and open access by the Master's Theses and Graduate Research at SJSU ScholarWorks. It has been accepted for inclusion in Master's Theses by an authorized administrator of SJSU ScholarWorks. For more information, please contact scholarworks@sjsu.edu. 
VARIATION IN ADRENAL AND THYROID HORMONES WITH LIFE-HISTORY STAGE IN JUVENILE NORTHERN ELEPHANT SEALS (MIROUNGA ANGUSTIROSTRIS)

\author{
A Thesis \\ Presented to \\ The Faculty of the Department of Biological Sciences \\ San Jose State University
}

In Partial Fulfillment

of the Requirements for the Degree

Master of Science

by

Jennifer Jelincic

May 2016 
(C) 2016

Jennifer Jelincic

ALL RIGHTS RESERVED 
The Designated Thesis Committee Approves the Thesis Titled

VARIATION IN ADRENAL AND THYROID HORMONES WITH LIFE-HISTORY STAGE IN JUVENILE NORTHERN ELEPHANT SEALS (MIROUNGA ANGUSTIROSTRIS)

By

Jennifer Jelincic

APPROVED FOR THE DEPARTMENT OF BIOLOGICAL SCIENCES

SAN JOSE STATE UNIVERSITY

MAY 2016

Dr. Scott Shaffer Department of Biological Sciences

Dr. Shelley Cargill Department of Biological Sciences

Dr. Daniel Crocker Sonoma State University 


\title{
ABSTRACT
}

\section{VARIATION IN ADRENAL AND THYROID HORMONES WITH LIFE-HISTORY STAGE IN JUVENILE NORTHERN ELEPHANT SEALS (MIROUNGA ANGUSTIROSTRIS)}

\author{
By Jennifer Jelincic
}

Interpretation of stress responses in wildlife is inadequate due to the range of natural variation and potential confounds of individual and life-history variables. In marine mammals, endocrine response data are sparse and variable across species. Blood adrenal and thyroid hormones were measured in 144 chemically immobilized yearling elephant seals at Año Nuevo State Reserve to characterize variation between sexes and across semiannual haul-outs. There was no relationship between hormone concentration and time needed for collecting blood or diel pattern, suggesting that concentrations represented baseline values. Serum cortisol concentrations did not vary with gender or across fasts but increased dramatically during molting. Cortisol was significantly correlated with aldosterone at all measured life-history. Thyroxine levels were lower in females and decreased with fasting in both sexes during the Fall haul-out. Cortisol concentrations were correlated with reverse T3 concentrations across all measured life-history stages suggesting an important impact of cortisol on deiodinase enzymes and thyroid function. Significant variation in stress hormone concentrations with gender and life-history stage emphasizes the importance of contextual variables when interpreting serum hormone concentrations. 


\section{ACKNOWLEDGEMENTS}

Many thanks \& appreciation to all of my committee members for their time \& effort. For Scott Shaffer's graciousness in taking me on \& giving me fieldwork (I do love the birds- but you couldn't keep me from mammals). Thank you to Shelley Cargill, for her quick, useful feedback \& Gitte Macdonald, for her great advice \& for pushing me to be better. I owe much to Dan Crocker, who has been amazing in the field, lab, at the computer, \& in Continental 6-9 at the MMC. Thank you to Shannon Bros, Jeff Honda, Shearon Threats, Jerry Smith, \& Larry Young for departmental support; Mike Tift, Cory Champagne, Dorian Houser, \& Stephen Tavoni for everything seals; \& countless undergraduates for lab support. Thank you to the ShAPE lab stanchions; especially Caitie Kroeger, Emma Kelsey, Lindsey Broadus, Anne Cassell, Sue Cockerham, Corey Clatterbuck, Abram Fleishman, Greg Taylor, Brad Wilkinson, \& Tim Walker. To Randi Cappelletti, Blair Bazdarich, Andrea Currylow, \& Emily Moffitt for being strong women in STEM. The Office of Naval Research funded this study, for which I am very grateful, \& both the Arthur \& Karin Nelson \& East Bay Zoological Society Scholarships funded me. I appreciate my colleagues at OZ, CAS, Safari West, WildAss, ARCAS, COAST, WHALE CITE, SCVWD, \& UCP who have given me opportunities and helped me learn my path. My family \& friends have been incredibly supportive throughout my time at SJSU, \& I love you all for it. And lastly, thank you Stephen- for your patience, love, and music. 


\section{TABLE OF CONTENTS}

List of Figures




\section{LIST OF FIGURES}

Figure 1. Serum cortisol levels ( $\mathrm{nM}$ ) are not impacted by $(A)$ the time from anethesia administration to time to sample ( $\mathrm{min}$ ) or (B) time of day (hrs) in juvenile northern elephant seals.....

Figure 2. The relationship between the percentage of molted fur (molt \%) and serum hormone concentrations in molting juvenile northern elephant seals

Figure 3. Whisker plots depicting mean, quartile, and standard deviations for stress hormone concentrations in molting juvenile northern elephant seals.

Figure 4. Associations between hormones in fasting juvenile northern elephant seals. 


\section{LIST OF TABLES}

Table 1. Mean values for ACTH and adrenal hormones across different life-history stages in juvenile northern elephant seals.

Table 2. Mean values for hormones that varied between sexes

Table 3. Mean values for thyroid hormones across different life-history states in juvenile northern elephant seals. 


\section{INTRODUCTION}

The vertebrate stress response has become increasingly important to the field of conservation physiology. Stressors can fall within several categories of perturbation including environmental, physiological, and psychosocial (i.e. fighting, social subordination, or lack of control). This response serves as a biomarker when examining individual and population health, physiological constraints, energy expenditure, habitat quality, and anthropogenic impacts (Romero, 2004). However, baseline stress hormone concentrations, and even the role of specific hormones, can vary widely among species, life-history stage and sex (Beiko et al., 2004; Kajantie and Phillips, 2006; Romero and Remage-Healey, 2000; Romero, 2002).

The activation of the hypothalamic-pituitary-adrenal (HPA) axis is central to the stress response. During an acute stress response, the HPA-axis is activated by the hypothalamus quickly releasing corticotropin-releasing hormone (CRH; Ma et al., 1997), which acts to stimulate the pituitary gland to release adrenocorticotropic hormone (ACTH; Antoni et al., 1984). ACTH influences the adrenal glands, releasing adrenocorticoids (i.e. cortisol and aldosterone) from the adrenal cortex (Haning et al., 1970). Catecholamines, such as epinephrine and norepinephrine, are also released as part of the fight-or-flight response to stress. Together, the suite of hormones activated by this response influence many processes in the body including heart rate, metabolic rate, energy allocation, growth, reproduction, immune response, memory, and 
behavior, allowing an animal to react appropriately to the stress, which ultimately promotes survival (Breuner et al., 2013; Brilion et al., 1995; Connell and Davies, 2005; Khani and Tayek, 2001; Maule et al., 1987; Romero and Butler, 2007; Tilbrook et al., 2000).

Because the regulation of metabolic rate is important to endotherms and the fight-or-flight response can disrupt this homeostatic process, other axes, such as the hypothalamic-pituitary-thyroid (HPT) axis, can become altered during the stress response as well. Activation of the HPA axis is associated with reductions in the release of thyroid stimulating hormone (TSH) and inhibition of conversion of thyroid hormone to biologically active forms (Charmandari et al., 2005). Deiodinase enzymes located within target tissues convert thyroxine (T4) to triiodothryonine (T3), the biologically active form of thyroid hormone or reverse T3 (rT3; Helmreich and Tylee, 2011), which binds to the thyroid receptor without activation. Thyroid hormones help regulate metabolic rate by altering expression of membrane ion pumps and can increase glucose oxidation rates in some species (Atkinson et al., 2011). Thyroid hormones can increase the metabolic clearance of cortisol (Thompson, 2007), as well as inducing the release of cortisol at inflammation sites (Zoeller et al., 2007). Under conditions of chronic stress, cortisol promotes the expression of deiodonase enzymes that produce rT3 from T4 (Helmreich and Tylee, 2011). 
With baseline glucocorticoid levels varying under different circumstances and affecting so many processes, it has been difficult to interpret stress hormone measurements in free-ranging animals (Cockrem, 2005; Heath and Frederick, 2005; Walker et al., 2005; Wikelski and Cooke, 2006). The effects of glucocorticoids on the impact of survival and fitness are not universal among species or individuals (Bonier et al., 2009; Busch and Hayward, 2009). The acute stress response is thought to be an adaptive response that could promote survival, but chronic activation of stress responses can have deleterious impacts on health and fitness (Chrousos, 2009; Stratakis and Chrousos, 1995). However, chronically high glucocorticoid levels at predictable lifehistory events could still be adaptive and beneficial for animals (Boonstra, 2013).

Sustained adaptive stress could reach a threshold, and ultimately influence an animal's ability to respond to any additional stressors (Romero, 2004). The ambiguity associated with interpreting stress and its consequences led to the concept of allostasis, which indicates an organism's ability to maintain stability through change (McEwen and Wingfield, 2003). Through allostasis, stability could be achieved through physiological or behavioral changes (Korte et al., 2005; McEwen and Wingfield, 2010), yet this idea did not allow for the range of potential responses to perturbations. The reactive scope model expanded the allostatic model of stress impacts, first identifying predictive and reactive homeostasis as normal conditions, compared with both homeostatic overload and failure, which can be pathological (Romero et al., 2009). 
Contextual information about natural adaptive variation in stress responses and the roles that stress hormones play in facilitating life-history transitions is critical to interpreting the fitness consequences of variation in baseline stress levels (Dantzer et al., 2014). However, the ecology and natural variation of these hormones in free-ranging animals is not understood for most species (Madliger and Love, 2014; Wikelski and Cooke, 2006). Without a general understanding of natural variation in stress responses, there is no way to identify the context for deleterious stress impacts or quantify the impact of additional stressors, such as those presented anthropogenically. For example, without this baseline data, there is no way to truly quantify the impact of ubiquitous noise on marine mammals (Wikelski and Cooke, 2006).

Marine mammals potentially experience a high amount of anthropogenic stressors including noise, pollution, impacts from overfishing, and water vehicle altercations (Brander, 2007; Derraik, 2002; Nowacek and Wells, 2001; Tanabe, 2002). Northern elephant seals (Mirounga angustirostris) provide an excellent framework for establishing baseline hormone concentrations across different stages because they haulout semi-annually and do not exhibit a stress response to chemical immobilization (Champagne et al., 2012). Prior to reaching breeding age, juvenile elephant seals haulout twice a year, once to molt in the Spring and a Fall haul-out that will later become the breeding haul-out after sexual maturity. Yearling elephant seals do not exhibit dimorphism in body size but have begun to show sex differences in metabolic regulation 
(Kelso et al., 2012). Both thyroid hormone concentrations (total T3 (tT3) and total T4 (tT4)) varied between sexes, and tT4 concentrations declined over the fasting period in juveniles (Kelso et al., 2012). Cortisol levels increased dramatically during molting (Champagne et al., 2015) but did not increase across the Fall haul-out in this age class (Kelso et al., 2012). Together these features make yearling elephant seals an ideal study group to explore sex differences and associations between stress hormones, not confounded by differences in reproductive effort or behavior.

Several pinniped populations are decreasing, and using a stable representative population, such as the northern elephant seals, can allow comprehension of how freeranging pinnipeds may ultimately respond to environmental stress beyond "normal" levels and whether variation in baseline stress is adaptive or pathological (Boonstra, 2013). Our objective was to establish baseline concentrations in cortisol, ACTH, aldosterone, epinephrine (EPI), norepinephrine (NE), total thyroxine (tT4), free thyroxine (fT4), total triidothyronine (fT3), free triidothyronine (fT3), and reverse T3 of juvenile northern elephant seals after returning from their second and third foraging trips at sea. We examined variation across contextual variables including diel patterns, life-history stage, sex, and associations between these stress hormones. 


\section{MATERIALS AND METHODS}

\section{Study Site and Subjects}

This study was conducted at Año Nuevo State Reserve in San Mateo County, CA, USA. Free-ranging yearlings (80 males, 64 females) were sampled during the Spring or Fall haul-out from September 2011 through May 2013. Animals were aged based on plastic flipper tags previously applied at weaning. Animals were then categorized by lifehistory stage, which was defined by the different haul-outs. During the Fall haul-out, biweekly surveys were performed to assess time on shore of individual seals. Subjects were categorized as early fast $(E F, n=53)$ if they had been on shore for $<7$ days and late fast $(L F, n=26)$ if they had been on shore for $>3$ weeks. During the Spring molt haul-out, subjects were classified based on their molt status. Early molt $(E M, n=16)$ subjects had no evidence of molting and late molt $(L M, n=16)$ subjects had completely shed their pelage. Mid-molt $(M M, n=34)$ subjects were in the process of molting and the percentage of their fur molted (Molt \%) was estimated visually and recorded. Additionally, mass $(\mathrm{kg})$, time of day, time to sample (how long after the animal was anesthetized the first blood sample was collected), and sex were recorded for all subjects.

Study animals were chemically immobilized using $\sim 1 \mathrm{mg} \mathrm{kg}^{-1}$ tiletaminezolazepam (Telazol) administered via intramuscular injection and anesthesia was maintained with intravenous doses of ketamine and diazepam as needed (all drugs, 
Fort Dodge Laboratories, Fort Dodge, IA, USA). Blood samples were drawn into serum, heparin, and EDTA vacutainer tubes with an 18-gauge needle from the extradural vein. Samples were stored on ice until transport to the lab, where they were centrifuged at $4^{\circ} \mathrm{C}$ and stored at $-80^{\circ} \mathrm{C}$ until analysis. Previous analysis had revealed degradation of catecholamine samples during the period of transport to the lab (Crocker, unpublished data). For this reason, samples for EPI and NE analysis were collected in EDTA vacutainers, centrifuged immediately on the beach and frozen on dry ice for transport to the lab.

\section{Hormone Analyses}

Hormone concentrations were measured via commercially available radioimmunoassay (cortisol, aldosterone, tT4, tT3, fT4, and fT3 from Siemens, Inc., Washington, DC, USA; reverse T3 (rT3) from Alpco, Inc. Salem, NH, USA) enzyme immunoassay (ACTH from Alpco, Inc., Salem, NH, USA), and enzyme-linked immunosorbent assay kits (EPI and NE from Alpco, Inc.). All assays have been validated

for use in elephant seals (Champagne et al., 2013, 2005; Ensminger et al., 2014; Ortiz et al., 2001). Mean intra-assay CV\% were $<3.5 \%$ and mean inter-assay CV\% were $<5.6 \%$ for all analytes.

\section{Data Analysis}

General linear models (GLM) were used to assess contextual variables in relation to hormones (JMP Pro 11, SAS Institute, Raleigh, NC). A GLM was fit for each hormone 
with sex, mass and life-history stage as fixed effects. Body mass had no effect on any hormone variable and was removed from all of the models before assessing the effects of sex and life-history stage. If the hormone concentrations varied with life-history stage, post hoc analyses were conducted using Student's t-tests to compare least square means. Model residuals were visually assessed for approximate normality and predicted vs. residuals plots were assessed for evidence of homoscedascity. When there were problems with heteroscedascity (aldosterone), data were log transformed. For each hormone, variation with life-history stages, sex, and mass were analyzed. Relationships between hormones were assessed using simple linear regression. All means are reported \pm standard error of the mean (SEM). Results were considered significant at $p<$ 0.05 .

\section{RESULTS}

\section{Changes in hormones with contextual variables}

When controlled for life-history stage there was no effect of time to sample on concentrations of serum cortisol $(p=0.67$; Figure $1 A)$, plasma NE $(p=0.24)$ or EPI $(p=0.83)$, suggesting that samples reflected baseline values. When controlled for life-history stage there was no effect of time of day on concentrations of serum cortisol $(p=0.24$, Figure 1B). 
Cortisol concentrations did not

differ between males and

females $(p=0.56)$, but were

impacted by life-history stage

$\left(F={ }_{4,138}=19.66, p=<.0001\right)$. Serum

cortisol levels were significantly

higher during the late molting

period compared to early molt,

and early and late fast. However,

the mid-molt stage was

significantly higher from all other

stages $(p<0.05 ;$ Table 1$)$. During the

mid-molt, cortisol increased as the

percentage of fur molted increased

(Figure 2A). Across all life-history

stages, there were some individuals
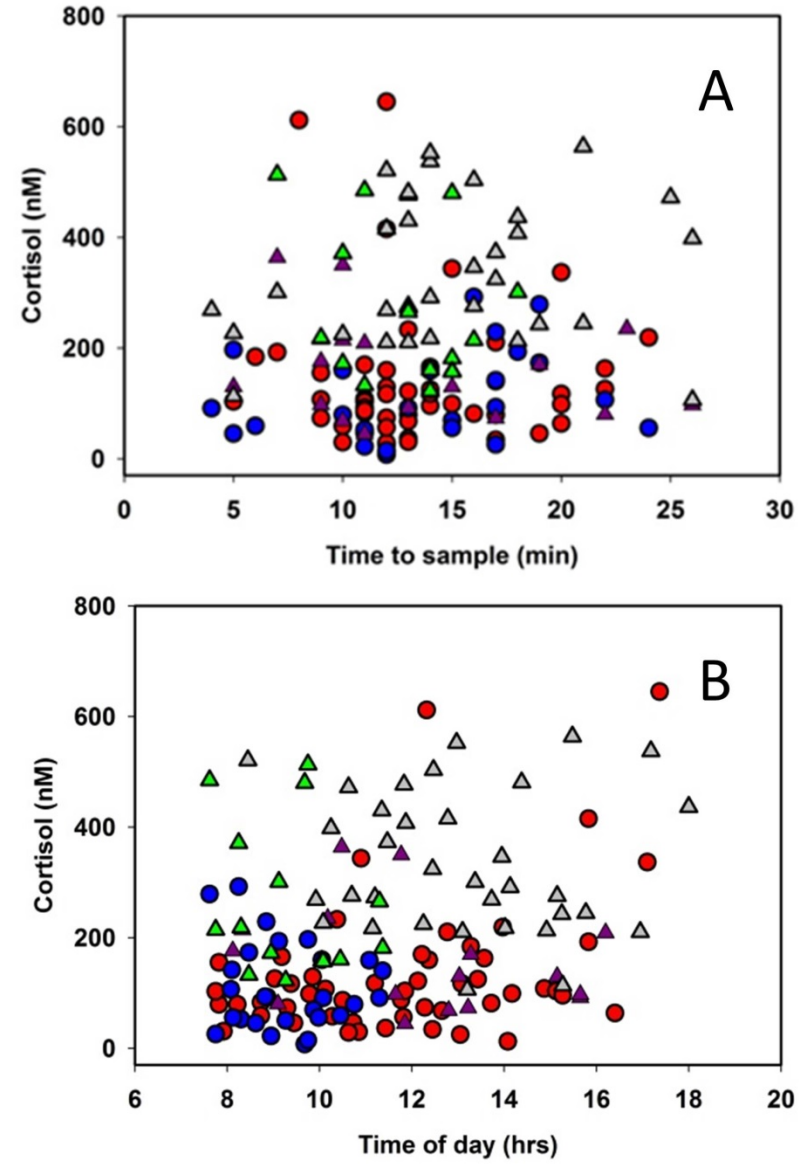

Figure 1. Serum cortisol levels (nM) are not impacted by $(A)$ the time from anesthesia administration to time to sample (min) or (B) time of day (hrs) in juvenile northern elephant seals, across life history stages. Red circles represent early fast, blue circles represent late fast, purple triangles represent early molt, gray triangles represent mid-molt, and green triangles represent late molt.

that exhibited cortisol levels

greater than 2 standard deviations above the mean of conspecifics (Figure 3B), suggesting atypically high baseline cortisol levels. 
Table 1. Mean values for ACTH and adrenal hormones across different life-history states in juvenile northern elephant seals. Ald: aldosterone, EPI: epinephrine, NE:

norepinephrine, EF: early fast, LF: late fast, EM: early molt, MM: mid-molt, LM: late molt

\begin{tabular}{llllll}
\hline & ACTH $(p M)$ & \multicolumn{1}{c}{ Cortisol $(n M)$} & \multicolumn{1}{c}{ Ald $(\mathrm{pM})$} & \multicolumn{1}{c}{ EPI $(\mathrm{pM})$} & \multicolumn{1}{c}{ NE $(\mathrm{pM})$} \\
\hline EF & $8.2 \pm 0.8^{\mathrm{A}}$ & $135.8 \pm 17.5^{\mathrm{A}}$ & $437.8 \pm 46.9^{\mathrm{A}}$ & $117.1 \pm 7.3^{\mathrm{A}}$ & $509.9 \pm 45.8^{\mathrm{A}, \mathrm{B}}$ \\
LF & $11.4 \pm 1.6^{\mathrm{A}, \mathrm{B}}$ & $110.8 \pm 15.6^{\mathrm{A}}$ & $327.5 \pm 46.6^{\mathrm{A}}$ & $207.1 \pm 18.4^{\mathrm{B}}$ & $603.6 \pm 61.0^{\mathrm{A}}$ \\
EM & $15.2 \pm 1.4^{\mathrm{B}, \mathrm{C}}$ & $158.1 \pm 24.1^{\mathrm{A}}$ & $381.4 \pm 74.2^{\mathrm{A}}$ & $118.7 \pm 9.6^{\mathrm{A}}$ & $408.3 \pm 35.5^{\mathrm{B}}$ \\
MM & $19.1 \pm 1.5^{\mathrm{C}}$ & $335.8 \pm 21.9^{\mathrm{B}}$ & $1237.5 \pm 129.1^{\mathrm{B}}$ & $94.1 \pm 9.3^{\mathrm{A}}$ & $433.7 \pm 33.3^{\mathrm{A}, \mathrm{B}}$ \\
LM & $14.9 \pm 1.8^{\mathrm{B}, \mathrm{C}}$ & $262.2 \pm 35.2^{\mathrm{C}}$ & $632.8 \pm 76.0^{\mathrm{C}}$ & $199.4 \pm 9.5^{\mathrm{B}}$ & $568.6 \pm 32.6^{\mathrm{A}}$ \\
\hline
\end{tabular}

Different superscripts denote significant differences between groups $(p<0.05)$ based on post-hoc

Students' t-test comparisons of least square means from the GLM containing sex and life-history stage as fixed effects.

ACTH concentrations did not vary with $\operatorname{sex}(p=0.65)$, but did vary with life-history stage $\left(F_{4,138}=12.14, p<.0001 ;\right.$ Figure $\left.3 A\right)$. ACTH levels during the mid-molt period were significantly greater than any other life-history stage, and the early fast had significantly lower values ( $p<.0001 ;$ Table 1$)$. Aldosterone concentrations did not differ with sex $(p=0.86)$, but did vary with life-history stage $\left(F_{4,139}=20.42, p=<.0001\right)$. The mid-molt exhibited significantly higher aldosterone concentrations than any other life-history stage and concentrations were still elevated at the end of the molt compared to other stages $(p<0.05$; Table 1; Figure $3 C)$.

Males had higher NE concentrations compared to females $\left(F_{1,85}=6.31 p=0.01\right.$; Table 2). NE concentrations varied among all life-history stages $\left(F_{4,82}=6.31 ; p=0.02\right)$ and were higher late in the haul-outs compared to the early molt samples $(p<0.5$; Table 1 ; Figure 3D). EPI concentrations did not vary with sex $(p=0.30)$, but did vary with life- 
history stage $\left(F_{4,81}=19.31, p=<0.0001\right)$.

EPI concentrations increased with

fasting. The late fasting and late molting

stages had significantly higher EPI levels

than any other life-history stage $(P<0.05$;

Table 1; Figure 3E).

In contrast to most adrenal hormones,

thyroid hormones varied with sex as well

as life-history stage. Serum tT4

concentrations were lower in females

compared to males $\left(F_{1,138}=5.72, p=0.02\right.$;

Table 2). tT4 varied with life-history stage

$\left(F_{4,138}=56.32, p<0.0001\right) . t T 4$

concentrations were highest in early fast

samples compared to all other stages and
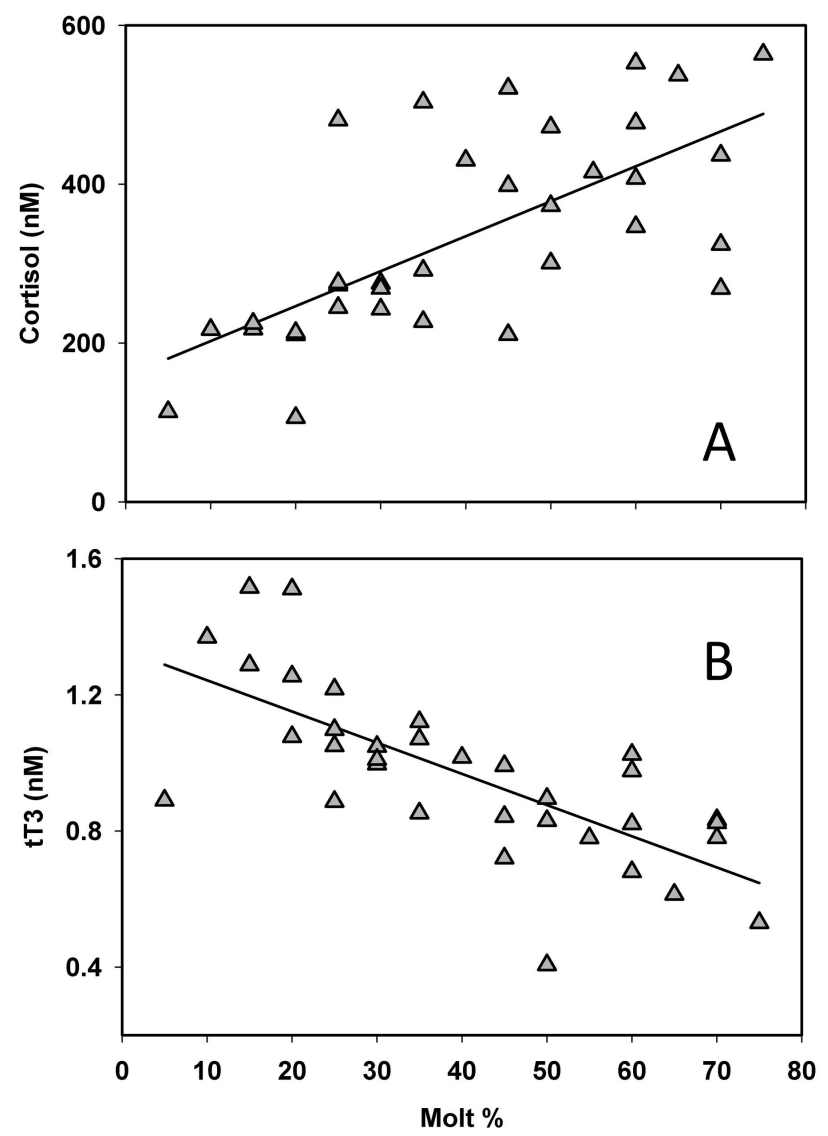

Figure 2. The relationship between the percentage of molted fur (molt \%) and serum hormone concentrations in molting juvenile northern elephant seals. A: cortisol $\left(y=4.40 x+158.3 ; r^{2}=0.45, F_{1,32}\right.$ $=26.52 ; p<0.001)$. B: tT3 $(y=0.009+1.34$; $\left.r^{2}=0.51, F_{1,32}=34.32 ; p<0.001\right)$

lowest in the early molt and mid-molt samples ( $<<0.05$; Table 3$)$. fT4 concentrations were higher in males than females $\left(F_{1,138}=11.74, p=0.001 ;\right.$ Table 2$)$. fT4 concentrations varied with life-history stage $\left(F_{4,138}=8.09, p<0.001\right)$ and were lower in mid-molt and late molt samples compared to other stages $(p<0.05$; Table 3$)$. 
Table 2. Mean values for hormones that varied between the sexes. NE: norepinephrine, tT4: total T4, fT4: free T4, tT3: total T3, fT3: free T3.

\begin{tabular}{|c|c|c|}
\hline & Males & Females \\
\hline NE (pM) & $552.4 \pm 23.3$ & $447.1 \pm 23.3$ \\
\hline tT4 (nM) & $58.8 \pm 1.9$ & $13.6 \pm 0.8$ \\
\hline fT4(pM) & $12.7 \pm 0.4$ & $10.4 \pm 0.5$ \\
\hline tT3 (nM) & $1.49 \pm 0.06$ & $1.20 \pm 0.04$ \\
\hline fT3 (pM) & $2.27 \pm 0.09$ & $1.77 \pm 0.09$ \\
\hline
\end{tabular}

Table 3. Mean values for thyroid hormones across different life-history states in juvenile northern elephant seals. tT4: total T4, fT4: free T4, tT3: total T3, fT3: free T3, rT3: reverse T3, EF: early fast, LF: late fast, EM: early molt, MM: mid-molt, LM: late molt

\begin{tabular}{lllrcr}
\hline & $\mathrm{tT4}(\mathrm{nM})$ & $\mathrm{fT} 4(\mathrm{pM})$ & $\mathrm{tT3}(\mathrm{nM})$ & $\mathrm{fT3}(\mathrm{pM})$ & $\mathrm{rT3}(\mathrm{nM})$ \\
\hline $\mathrm{EF}$ & $84.7 \pm 3.0^{\mathrm{A}}$ & $12.7 \pm 0.6^{\mathrm{A}}$ & $1.54 \pm 0.06^{\mathrm{A}}$ & $2.34 \pm 0.10^{\mathrm{A}, \mathrm{B}}$ & $1.85 \pm 0.08^{\mathrm{A}}$ \\
LF & $58.8 \pm 1.9^{\mathrm{B}}$ & $13.6 \pm 0.8^{\mathrm{A}}$ & $1.64 \pm 0.06^{\mathrm{A}}$ & $2.30 \pm 0.12^{\mathrm{A}, \mathrm{B}}$ & $2.25 \pm 0.11^{\mathrm{B}}$ \\
EM & $36.2 \pm 2.6^{\mathrm{C}}$ & $9.0 \pm 1.0^{\mathrm{A}}$ & $1.25 \pm 0.05^{\mathrm{B}}$ & $2.01 \pm 0.19^{\mathrm{B}}$ & $1.72 \pm 0.16^{\mathrm{A}}$ \\
$\mathrm{MM}$ & $38.8 \pm 7.5^{\mathrm{C}}$ & $9.5 \pm 0.5^{\mathrm{B}}$ & $0.97 \pm 0.04^{\mathrm{C}}$ & $1.22 \pm 0.08^{\mathrm{C}}$ & $2.37 \pm 0.13^{\mathrm{B}}$ \\
LM & $55.3 \pm 14.2^{\mathrm{B}}$ & $12.8 \pm 0.5^{\mathrm{B}}$ & $1.25 \pm 0.04^{\mathrm{B}}$ & $2.46 \pm 0.22^{\mathrm{A}}$ & $2.50 \pm 0.17^{\mathrm{B}}$ \\
\hline
\end{tabular}

Different superscripts denote significant differences between groups $(p<0.05)$ based on post-hoc Students' t-test comparisons of least square means from the GLM.

tT3 concentrations were higher in males compared to females $\left(F_{1,138}=8.22 p=0.005\right.$;

Table 2). tT3 concentrations varied with life-history stage $\left(F_{4,138}=8.09, p<0.001\right)$ and were suppressed during the molt when compared to the Fall haul-out $(p<0.05$; Table 3). tT3 concentrations declined linearly with the progression of pelage loss $\left(r^{2}=0.51, F_{1}\right.$, $32=34.32 ; p<0.001)$. fT3 concentrations were higher in males compared to females $\left(F_{1,138}=8.19 p=0.005 ;\right.$ Table 2). 

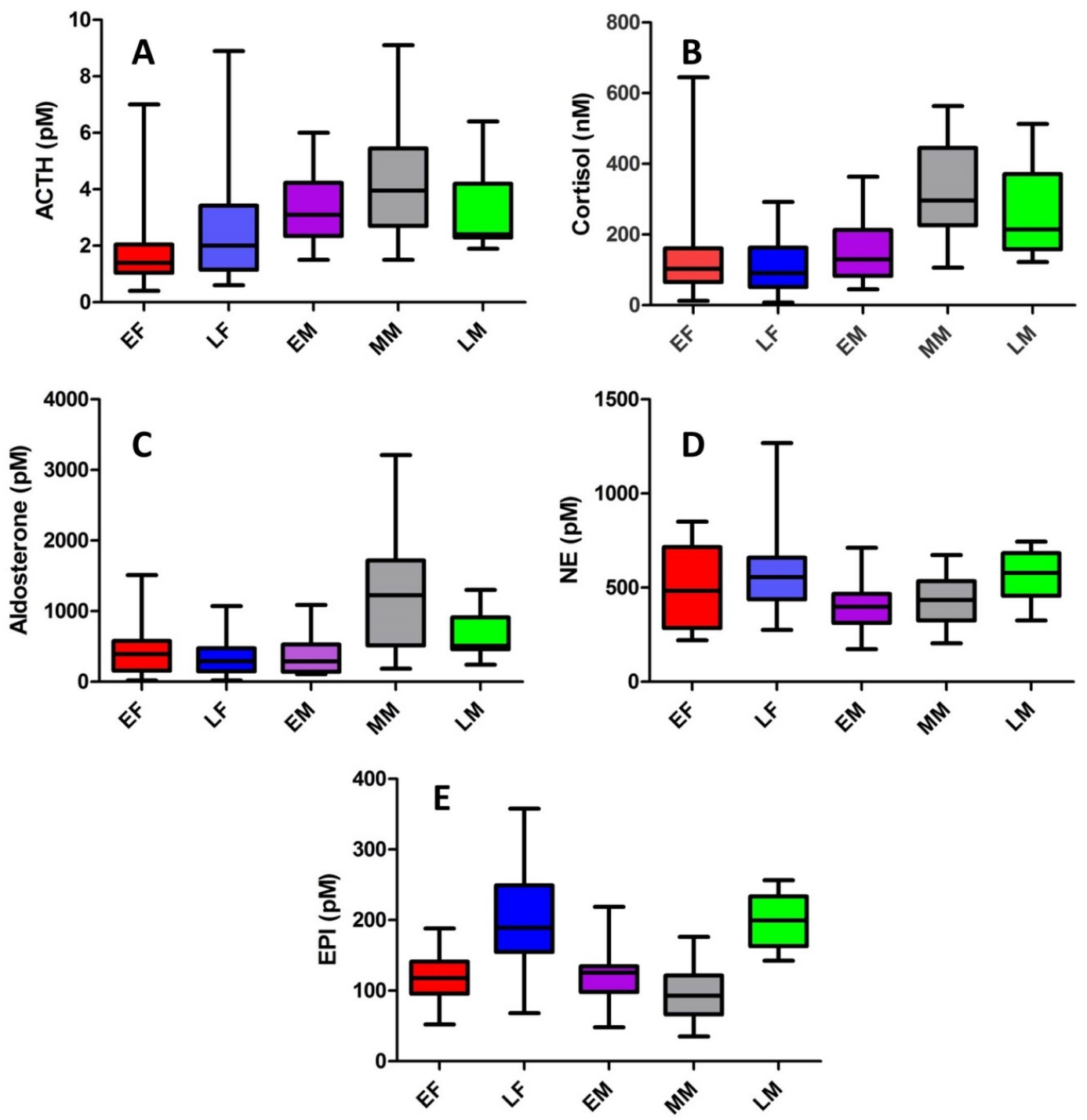

Figure 3. Whisker plots depicting mean, quartile, and standard deviations for stress hormones in juvenile northern elephant seals. A: ACTH, B: Cortisol, C: Aldosterone, D: Norepinephrine (NE), and E: Epinephrine (EPI). Red circles represent early fast, blue circles represent late fast, purple triangles represent early molt, gray triangles represent mid-molt, and green triangles represent late molt. 

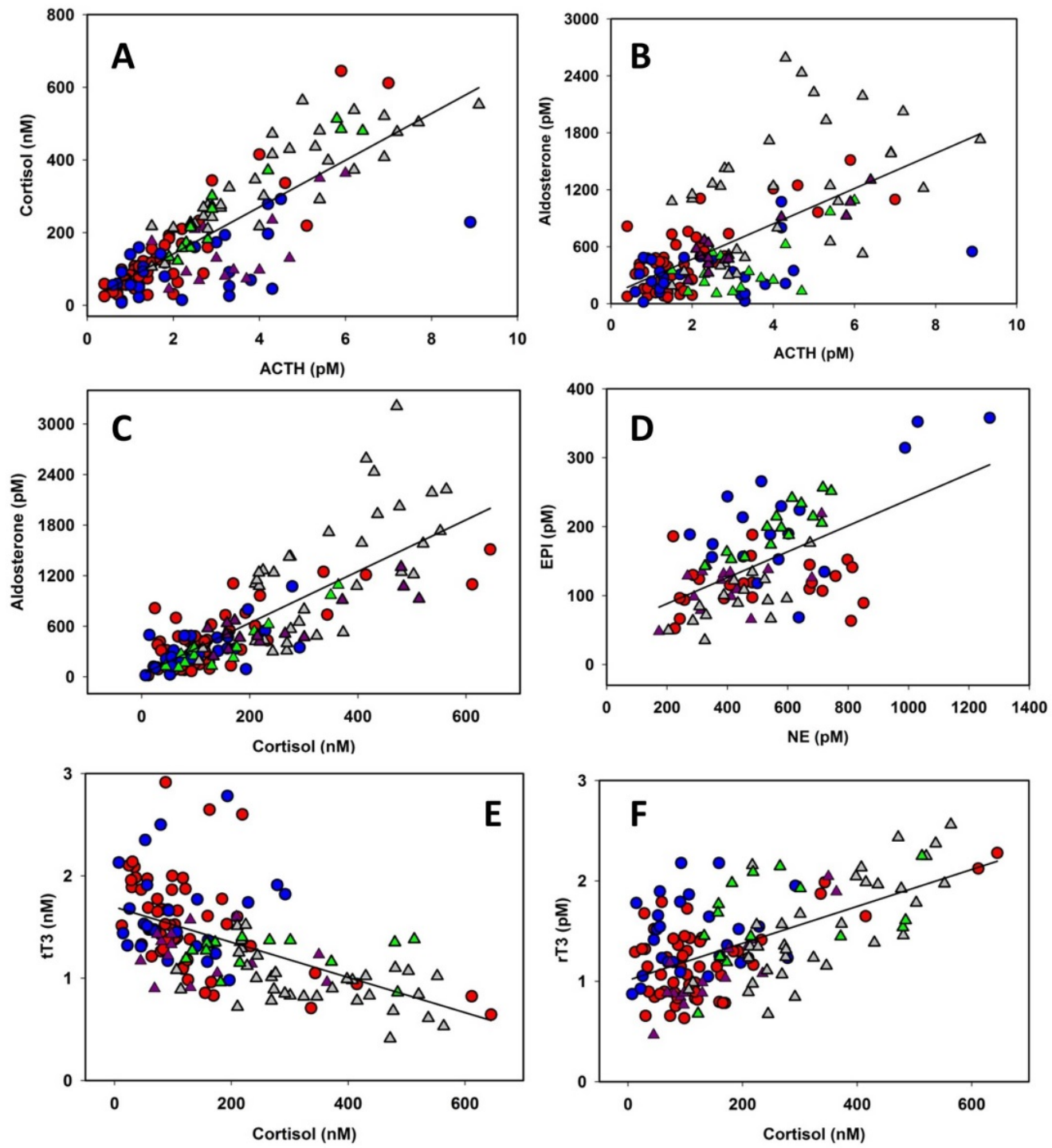

Figure 4. Associations between hormones in fasting juvenile northern elephant seals. A: ACTH vs. cortisol, B: ACTH vs. aldosterone, C: cortisol vs. aldosterone, D: norepinephrine (NE) vs. epinephrine (EPI), E: cortisol vs. total T3 (tT3), F: cortisol vs. reverse T3 (rT3). Red circles represent early fast, blue circles represent late fast, purple triangles represent early molt, gray triangles represent mid-molt, and green triangles represent late molt. 
fT3 concentrations varied with life-history stage $\left(F_{4,138}=14.41, p<0.001\right)$ and were suppressed in mid-molt samples when compared to all other life-history stages $(p<$ 0.05; Table 3). In contrast to the other thyroid hormones, rT3 did not vary with sex ( $p>$ 0.05). rT3 concentrations varied with life-history stage $F_{4,138}=6.15, p<0.001$ ) and were higher during the molt stages compared to the samples from the Fall haul-out $(p<0.05$; Table 3).

\section{Associations between hormones}

When data from all life-history stages and sexes were combined, several strong relationships between hormones were evident. Serum cortisol increased linearly with increasing ACTH concentrations $\left(r^{2}=0.83, F_{1,142}=274.12, p<.0001 ;\right.$ Figure $\left.4 A\right)$ as did aldosterone $\left(r^{2}=0.36, F_{1,142}=80.61, p<.0001 ;\right.$ Figure 4B). Cortisol concentrations were strongly associated with aldosterone concentrations $\left(r^{2}=0.62, F_{1,142}=228.54, p<.0001\right.$;

Figure 4C. EPI \& NE concentrations were positively associated across all life-history stages $(r 2=0.33, F 1,85=41.44, p<.0001$, Figure 4D).

tT3 concentrations were inversely associated with cortisol concentrations $\left(r^{2}=0.31 ; F_{1,142}=63.85, p<0.0001\right.$, Figure 4E $)$ and fT3 concentrations exhibited a weaker inverse association with cortisol $\left(r^{2}=0.12, F_{1,142}=18.78, p<0.0001\right) . r T 3$ concentrations were positively associated with cortisol $\left(r^{2}=0.36, F_{1,142}=78.94, p<\right.$ 
0.0001, Figure 4F); tT4 and fT4 concentrations were not associated with cortisol ( $p>$ 0.05).

\section{DISCUSSION}

Endocrine stress studies are often unable to obtain accurate baseline hormone concentrations due to handling causing a stress response (Madliger and Love, 2014). Therefore, we had to assess whether blood samples taken under chemical immobilization represented baseline hormone concentrations or were impacted by a stress response to handling. The samples included handling times that ranged from animals that accidently received the initial injection intravenously and were sampled within minutes to animals that required additional immobilization drugs for sampling. There was no effect of sampling time on cortisol or catecholamine concentrations suggesting that northern elephant seals do not react with an endocrine stress response to immobilization and sampling using dissociative drugs. This large cross-sectional finding supports previous findings of lack of significant change in cortisol concentrations during longitudinal sampling over hours of immobilization (Champagne et al., 2012). In contrast to numerous species that exhibit strong diurnal patterns in cortisol concentrations (Fries et al., 2009; Hellhammer et al., 2007; Peter et al., 1978; Smyth et al., 1997; Stone et al., 2001), there was no diurnal pattern evident in elephant seals. Together, these findings suggest that the hormone measurements in the current study 
reflect baseline levels and can be used to examine life-history variation in adrenal hormones.

Previous studies in captive phocids have suggested diurnal variation in cortisol (e.g., Gardiner and Hall, 1997). Although these findings may reflect species differences, our findings suggest this difference might reflect the feeding regimens entrained in captive animals. The lack of diel pattern seen in wild juvenile elephant seals is consistent with the fact that elephant seals feed intensively at night (Robinson et al., 2012) and do not show diel patterns to behavior when hauled out on shore (Crocker et al., 2012). While this finding may not generalize to species with strong diel patterns in feeding and behavior (Boyd et al., 1994; Horning and Trillmich, 1999; Mclntyre et al., 2011; Watanabe et al., 2004), it suggests caution in inferring diel patterns from captive animals.

Cortisol did not increase with fasting duration except during molting. Previous studies have demonstrated dramatic increases in serum cortisol concentrations during fasting duration in weaned pups and lactating females (Champagne et al., 2005; Ortiz et al., 2001). This pattern was thought to reflect increased needs for lipolysis during lactation and development (Fowler et al., 2016). In contrast, breeding adult males showed no consistent increase in cortisol despite fasting durations and rates of energy expenditure that greatly exceed those of conspecifics (Crocker et al., 2012). This difference was hypothesized to reflect either a need to avoid glucocorticoid stimulation 
of proteolysis during an extended fast or due to high cortisol levels early in fasting from male competition (Crocker et al., 2012). A smaller sample study in juveniles during the Fall haul-out showed a similar lack of elevation in cortisol during fasting (Kelso et al., 2012). We found that cortisol levels do not increase consistently when juveniles are only fasting (Fall haul-out), but do elevate during the molt, with the highest values occurring mid-molt. The strong association with the progression of the molt (Figure 2; 4B; Table 1) suggests an important role for cortisol elevation in promoting the shedding phase of the catastrophic molt.

In a recent study in molting juvenile northern elephant seals, the HPA axis remained sensitive to ACTH stimulation regardless of varying baseline levels of glucocorticoids (Champagne et al., 2015). If sampled at the appropriate temporal scale, ACTH should be predictive of concentrations of cortisol concentrations in normal HPA axis regulation. However, ACTH is secreted in a pulsatile fashion that is influenced by age, gender, and body condition in model systems (Veldhuis et al., 2009). This pattern has not been established for elephant seals or other pinnipeds. Pulsatile secretion, more rapid clearance of peptide hormones relative to the slower turnover of carrier-protein bound cortisol, and negative feedback of cortisol on the HPA axis may decouple the relationship between $\mathrm{ACTH}$ and cortisol in point measurements. The strong association of plasma ACTH and serum cortisol despite these potential confounds supports the suggestion that samples reflected stable baseline hormone levels. 
Cortisol was strongly associated with aldosterone levels in juvenile elephant seals across all life-history stages. The mid-molt period exhibiting the highest aldosterone concentrations and a decrease in both late fasting and late molting is identical to the pattern exhibited during a previous ACTH challenge study (Champagne et al., 2015). The similarity seen in free-ranging baseline concentrations and the ACTH challenge supports control by the HPA axis. Aldosterone is normally associated with regulation of blood pressure and electrolyte balance and regulated by the reninangiotensin system (RAS). Renin is released in response to low renal tubular flow rates and converts angiotensinogen to angiotensin I, which is then changed to angiotensin II by a converting enzyme in the pulmonary vasculature. Angiotensin II then promotes release of aldosterone by the adrenal gland. Several studies have suggested that aldosterone is an important component of the stress response in marine mammals, being released in response to an ACTH challenge or perceptual stress (Champagne et al., 2015; Gulland et al., 1999; Houser et al., 2011; Thomson and Geraci, 1986). The regulation of aldosterone release by the HPA axis may reflect the need to alter kidney perfusion and lung perfusion during diving, inhibiting typical RAS regulation (Atkinson et al., 2015). In contrast to the juveniles in the current study, aldosterone concentrations increased across the breeding fast in adult male elephant seals (Champagne et al., 2006; Ortiz et al., 2006) in association with RAS activation suggesting that this hormone may be under dual regulation by the HPA axis and RAS. 
Catecholamine concentrations increased across the fast. EPI, NE, and cortisol are not only all involved in the stress response, but all three hormones are also involved in inducing lipolysis. Increased lipid store availability is especially important in animals that undergo long-term fasting (Jensen et al., 1987; Rizack, 1961), with fatty acid oxidation providing energy and assisting in glucose-dependent tissue metabolic requirements (Houser et al., 2007). The catecholamine concentration increase across both types of fasts and the lack of a parallel cortisol concentration increase suggests a baseline concentration measurement as well as an important role of EPI and NE in fasting northern elephant seals.

$\mathrm{EPI}$ and NE are also involved in the dive response in marine mammals (Atkinson et al., 2015). The splenic contraction and circulatory adjustments (e.g., bradycardia) that occur in diving pinnipeds are associated with increased catecholamine concentrations (Cabanac et al., 1997; Hance et al., 1982; Hochachka et al., 1995). Though these patterns are consistent with our findings, a previous study reported that weaned northern elephant seal pups experienced a decrease in EPI levels from early to mid-fast (Tavoni et al., 2013). The regulatory role of EPI during fasting is to stimulate fatty acid release and inhibit glucose uptake by peripheral tissues (Rizack, 1961), therefore this difference could be attributed to a much smaller sample size, length of fast, or a different age group. However, the changes measured in the current study are consistent 
with the increased nutrient mobilization and reduced insulin sensitivity found in some tissues in elephant seals (Viscarra et al. 2013).

Male juvenile northern elephant seals had higher NE concentrations across all life-history stages. While EPI increases metabolic rate, enhances glycogenolysis, and increases release of glucose into the blood stream, NE plays key roles in homeostasis of blood volume and blood pressure (Atkinson et al., 2015). Previously, juvenile northern elephant seals exhibited sex differences in both fuel metabolism and energy expenditure during fasting (Kelso et al., 2012). Sex differences in energy expenditure may reflect thyroid-mediated differences in metabolism but may also reflect different activity budgets when hauled out on shore. Sex differences in NE concentrations may reflect differences in time spent in the water or terrestrial apneas prior to sampling.

Previous investigations on thyroid hormones in elephant seals have revealed important differences between life-history stages in patterns associated with fasting. Thyroid hormones increase across the fast in developing weaned pups (Ortiz et al. 2003; Somo et al. 2015). Weaned pups show increased expression of deiodonase enzymes and thyroid receptor in adipose and muscle (Martinez et al. 2013) over fasting. In contrast, thyroid hormones did not change significantly across the extended breeding fast in adult male elephant seals (Crocker et al., 2012). This response was thought to be due to the effects of protein sparing, with the elevation in tT3 across the fast influencing the degree of protein catabolism. In contrast to weaned pups and adult males, juveniles 
displayed more of a typical mammalian fasting response, with tT4 suppressed across fasting (Kelso et al. 2012). In the current study, we replicated this finding but found no changes in the free form of T4 that would be available to tissues for deiodination. In contrast, rT3 concentrations increased with fasting during the Fall haul-out suggesting the potential for metabolic suppression across the fast. Fasting grey seal pups showed sex difference T4 patterns during fasting, with females having higher T4 levels early in the fast and decreasing over time, while males did not decrease (Bennett et al., 2012). It has been suggested that the lack of decline in thyroid hormones could be due to the conflict between fasting fuel conservation and lipolysis for development and fat-based metabolism (Bennett et al., 2012).

Large changes in thyroid hormones took place during the molt, but these changes appeared to be related to the molt process, not fasting duration. tT4 and fT4 declined prior and during the molt, returning to similar levels to the Fall haul-out after molting. Serum tT3 and fT3 concentrations were strongly suppressed during the molt process ( $22 \%$ and $39 \%$ respectively) and returned to higher levels after molting. Serum rT3 increased during molting and remained high. The associations between cortisol and tT3 and rT3 across all life-history stages was influenced by the wide variation in the 3 hormones during molting and suggests an important role for cortisol influenced diodination in regulating T3 and rT3. Similar patterns in cortisol and thyroid hormones 
(elevated cortisol and suppressed T3 during the molt) have been reported in captive harbor seals and spotted seals (Ashwell-Erickson et al. 1986).

Stress studies are especially important in conservation because though the acute stress response is considered adaptive, additional stressors, such as anthropogenic stressors, can impact the ability of free-ranging animals to respond to additional, unpredictable stress (Romero et al., 2009). The lack of diel pattern and anesthesia impacts in cortisol concentrations in northern elephant seals will allow for a larger breadth of potential sampling time and method, which are both traditionally issues in field studies. We have also shown there is significant variation in stress hormone concentrations with gender and life-history stage. The sex differences seen in T4, as well as the decrease in concentrations in both sexes seen during the Fall further provide support for the significant variation in hormones across life-history stages. The early Fall haul-out is a key period to access juvenile baseline stress hormones because the impacts of extended fasting, molting, and reproduction are not present. Baseline cortisol levels can be measured from blood samples during this time, a critical survival period, which can potentially allow for the identification of allostatic shifts in baseline cortisol. Significant variation in hormone concentrations with gender and life-history stage emphasizes the importance of contextual variables when interpreting serum hormone concentrations in wildlife studies. 


\section{LITERATURE CITED}

Antoni FA, Holmes MC, Makara GB, Karteszi M, Laszlo FA (1984) Evidence that the effects of argenine-8-vasopressin (AVP) on pituitary corticotropin (ACTH) release are mediated by a novel type of receptor. Peptides 5: 519-522.

Atkinson S, Arnould JPY, Mashburn KL (2011) Plasma cortisol and thyroid hormone concentrations in pre-weaning Australian fur seal pups. Gen Comp Endocrinol 172: 277-281.

Atkinson S, Crocker D, Houser D, Mashburn K (2015) Stress physiology in marine mammals: how well do they fit the terrestrial model? J Comp Physiol B 1-24.

Beiko J, Lander R, Hampson E, Boon F, Cain DP (2004) Contribution of sex differences in the acute stress response to sex differences in water maze performance in the rat. Behav Brain Res 151: 239-253.

Bennett KA, Moss SEW, Pomeroy P, Speakman JR, Fedak MA (2012) Effects of handling regime and sex on changes in cortisol, thyroid hormones and body mass in fasting grey seal pups. Comp Biochem Physiol Part A 161: 69-76.

Bonier F, Martin PR, Moore IT, Wingfield JC (2009) Do baseline glucocorticoids predict fitness? Trends Ecol Evol 24: 634-642.

Boonstra R (2013) Reality as the leading cause of stress: rethinking the impact of chronic stress in nature. Funct Ecol 27: 11-23.

Boyd IL, Arnould JPY, Barton T, Croxall JP (1994) Foraging Behavior of Antarctic Fur Seals during Periods of Contrasting Prey Abundance. J Anim Ecol 63: 703-713.

Brander KM (2007) Global fish production and climate change. Proc Natl Acad Sci U S A 104: 19709-19714.

Breuner CW, Delehanty B, Boonstra R (2013) Evaluating stress in natural populations of vertebrates: total CORT is not good enough. Funct Ecol 27: 24-36.

Brilion DJ, Zheng B, Campbell RG, Matthews DE (1995) Effect of cortisol on energy expenditure and amino acid metabolism in humans. Am J Physiol Metab 268: E501E513.

Busch DS, Hayward LS (2009) Stress in a conservation context: A discussion of glucocorticoid actions and how levels change with conservation-relevant variables. Biol Conserv 142: 2844-2853. 
Cabanac a, Folkow LP, Blix a S (1997) Volume capacity and contraction control of the seal spleen. J Appl Physiol 82: 1989-1994.

Champagne C, Tift M, Houser D, Crocker D (2015) Adrenal sensitivity to stress is maintained despite variation in baseline glucocorticoids in moulting seals. Conserv Physiol 3: 1-11.

Champagne CD, Boaz SM, Fowler M a., Houser DS, Costa DP, Crocker DE (2013) A profile of carbohydrate metabolites in the fasting northern elephant seal. Comp Biochem Physiol - Part D Genomics Proteomics 8: 141-151.

Champagne CD, Houser DS, Costa DP, Crocker DE (2012) The effects of handling and anesthetic agents on the stress response and carbohydrate metabolism in northern elephant seals. PLoS One 7: e38442.

Champagne CD, Houser DS, Crocker DE (2005) Glucose production and substrate cycle activity in a fasting adapted animal, the northern elephant seal. J Exp Biol 208: 859868.

Champagne CD, Houser DS, Crocker DE (2006) Glucose metabolism during lactation in a fasting animal, the northern elephant seal. Am J Physiol Regul Integr Comp Physiol 291: R1129-R1137.

Charmandari E, Tsigos C, Chrousos G (2005) Endcrinology of the stress response. 1. Annu Rev Physiol 67: 259-284.

Chrousos GP (2009) Stress and disorders of the stress system. Nat Rev Endocrinol 5: 374-381.

Cockrem JF (2005) Conservation and behavioral neuroendocrinology. Horm Behav 48: 492-501.

Connell JMC, Davies E (2005) The new biology of aldosterone. J Endocrinol 186: 1-20.

Crocker DE, Houser DS, Webb PM (2012) Impact of body reserves on energy expenditure, water flux, and mating success in breeding male northern elephant seals. Physiol Biochem Zool 85: 11-20.

Crocker DE, Ortiz RM, Houser DS, Webb PM, Costa DP (2012) Hormone and metabolite changes associated with extended breeding fasts in male northern elephant seals (Mirounga angustirostris). Comp Biochem Physiol - A Mol Integr Physiol 161: 388394. 
Dantzer B, Fletcher Q, Boonstra R, Sheriff M (2014) Measures of physiological stress: a transparent or opaque window into the status, management and conservation of species? Conserv Physiol 2: 1-18.

Derraik JGB (2002) The pollution of the marine environment by plastic debris: A review. Mar Pollut Bull 44: 842-852.

Ensminger DC, Somo DA, Houser DS, Crocker DE (2014) Metabolic responses to adrenocorticotropic hormone (ACTH) vary with life-history stage in adult male northern elephant seals. Gen Comp Endocrinol 204: 150-157.

Fries E, Dettenborn L, Kirschbaum C (2009) The cortisol awakening response (CAR): Facts and future directions. Int J Psychophysiol 72: 67-73.

Gardiner KJ, Hall AJ (1997) Diel and annual variation in plasma cortisol concentrations among wild and captive harbor seals (Phoca vitulina). Can J Zool 75: 1773-1780.

Gulland FMD, Haulena M, Hilliard B (1999) Adrenal Function in Wild and Rehabilitated Pacific Harbor Seals ( Phoca vitulina richardsii ). Mar Mammal Sci 15: 810-827.

Hance AJ, Robin ED, Halter JB, Lewiston N, Robin DA, Cornell L, Caligiuri M, Theodore J (1982) Hormonal changes and enforced diving in the harbor seal Phoca vitulina. II. Plasamcatecholamines. Am J Physiol 242: R528-R532.

Haning R, Tait SAS, Tait JF (1970) In Vitro effects of ACTH, Angiotensins, Serotonin and Potassium on Steroid Output and Conversion of Corticosterone to Aldosterone by Isolated Adrenal Cells. Endocrinology 87: 1147-1167.

Heath JA, Frederick PC (2005) Relationships among mercury concentrations, hormones, and nesting effort of white ibises (Eudocimus albus) in the Florida everglades. Auk 122: 255-267.

Hellhammer J, Fries E, Schweisthal OW, Schlotz W, Stone AA, Hagemann D (2007) Several daily measurements are necessary to reliably assess the cortisol rise after awakening: State- and trait components. Psychoneuroendocrinology 32: 80-86.

Helmreich DL, Tylee D (2011) Thyroid hormone regulation by stress and behavioral differences in adult male rats. Horm Behav 60: 284-91.

Hochachka PW, Liggins GC, Guyton GP, Schneider RC, Stanek KS, Hurford WE, Creasy RK, Zapol DG, Zapol WM (1995) Hormonal regulatory adjustments during voluntary diving in Weddell seals. Comp Biochem Physiol - B Biochem Mol Biol 112: 361-375. 
Horning M, Trillmich F (1999) Lunar cycles in diel prey migrations exert a stronger effect on the diving of juveniles than adult Galápagos fur seals. Proc Biol Sci 266: 11271132.

Houser DS, Champagne CD, Crocker DE (2007) Lipolysis and glycerol gluconeogenesis in simultaneously fasting and lactating northern elephant seals. Am J Physiol Regul Integr Comp Physiol 293: R2376-81.

Houser DS, Yeates LC, Crocker DE (2011) Cold stress induces an adrenocortical response in bottlenose dolphins (Tursiops truncatus). J Zoo Wildl Med 42: 565-71.

Jensen MD, Haymond MW, Gerich JE, Cryer PE, Miles JM (1987) Lipolysis during fasting: decreased suppression by insulin and increased stimulation by epinephrine. $J$ Clin Invest 79: 207-213.

Kajantie E, Phillips DIW (2006) The effects of sex and hormonal status on the physiological response to acute psychosocial stress 151-178.

Kelso EJ, Champagne CD, Tift MS, Houser DS, Crocker DE (2012) Sex differences in fuel use and metabolism during development in fasting juvenile northern elephant seals. J Exp Biol 215: 2637-2645.

Khani S, Tayek JA (2001) Cortisol increases gluconeogenesis in humans : its role in the metabolic syndrome 747: 739-747.

Korte SM, Koolhaas JM, Wingfield JC, McEwen BS (2005) The Darwinian concept of stress: benefits of allostasis and costs of allostatic load and the trade-offs in health and disease. Neurosci Biobehav Rev 29: 3-38.

Leppäluoto J, Pääkkonen T, Korhoenen I, Hassi J (2005) Pituitary and autonomic responses to cold exposures in man. Acta Physiol Scand 184: 255-264.

Ma X, Levy A, Lightman SL (1997) Emergence of an Isolated Arginine Vasopressin (AVP) Response to Stress after Repeated Restraint: A Study of Both AVP and Corticotropin-Releasing Hormone Messenger Ribonucleaic Acid (RNA) and Heteronuclear RNA. Endocrinology 138: 4351-4357.

Madliger CL, Love OP (2014) The need for a predictive, context-dependent approach to the application of stress hormones in conservation. Conserv Biol 28: 283-287.

Maule AG, Schreck CB, Kaattari SL (1987) Changes in the immune sysem of coho salmon (Oncorhynchus kisutch) during the parr-to-smolt transformation and after implantation of cortisol. Canadaian J Fish Aquat Sci 44: 161-166. 
McEwen BS, Wingfield JC (2003) The concept of allostasis in biology and biomedicine. Horm Behav 43: 2-15.

McEwen BS, Wingfield JC (2010) What is in a name? Integrating homeostasis, allostasis and stress. Horm Behav 57: 105-111.

McIntyre T, Bornemann H, PlVdtz J, Tosh C, Bester M (2011) Water column use and forage strategies of female southern elephant seals from Marion Island. Mar Biol 158: 2125-2139.

Nowacek SM, Wells RS (2001) Short-term effects of boat traffic on bottlenose dolphins, Turciops truncatus, in Sarasota bay, Florida. Mar Mammal Sci 17: 673-688.

Ortiz RM, Crocker DE, Houser DS, Webb PM (2006) Angiotensin II and aldosterone increase with fasting in breeding adult male northern elephant seals (Mirounga angustirostris). Physiol Biochem Zool 79: 1106-12.

Ortiz RM, Wade CE, Ortiz CL (2001) Effects of prolonged fasting on plasma cortisol and TH in postweaned northern elephant seal pups. Am J Physiol Integr Comp Physiol 280: R790-R795.

Peter RE, Hontela A, Cook AF, Paulencu CR (1978) Daily cycles in serum cortisol levels in the goldfish: effects of photoperiod, temperature, and sexual condition. Can J Zool 56: $2443-2448$.

Rizack MA (1961) An epinephrine-sensitive lipolytic activity in adipose tissue. J Biol Chem 236: 657-662.

Robinson PW, Costa DP, Crocker DE, Gallo-Reynoso JP, Champagne CD, Fowler MA, Goetsch C, Goetz KT, Hassrick JL, Hückstädt LA, et al. (2012) Foraging Behavior and Success of a Mesopelagic Predator in the Northeast Pacific Ocean: Insights from a Data-Rich Species, the Northern Elephant Seal. PLoS One 7: e36728.

Romero LM (2002) Seasonal changes in plasma glucocorticoid concentrations in freeliving vertebrates. Gen Comp Endocrinol 128: 1-24.

Romero LM (2004) Physiological stress in ecology: lessons from biomedical research. Trends Ecol Evol 19: 249-255.

Romero LM, Dickens MJ, Cyr NE (2009) The reactive scope model - A new model integrating homeostasis, allostasis, and stress. Horm Behav 55: 375-389.

Romero LM, Remage-Healey L (2000) Daily and Seasonal Variation in Response to Stress in Captive Starlings (Sturnus vulgaris): Corticosterone. Gen Comp Endocrinol 119: 52-59. 
Romero ML, Butler LK (2007) Endocrinology of Stress. Int J Comp Psychol 20: 89-95.

Smyth JM, Ockenfels MC, Gorin AA, Catley D, Porter LS, Kirschbaum C, Hellhammer DH, Stone A a. (1997) Individual differences in the diurnal cycle of cortisol.

Psychoneuroendocrinology 22: 89-105.

Stone A a., Schwartz JE, Smyth J, Kirschbaum C, Cohen S, Hellhammer D, Grossman S (2001) Individual differences in the diurnal cycle of salivary free cortisol: A replication of flattened cycles for some individuals. Psychoneuroendocrinology 26: 295-306.

Stratakis C a., Chrousos GP (1995) Neuroendocrinology and pathophysiology of the stress system. Ann N Y Acad Sci 771: 1-18.

Tanabe S (2002) Contamination and toxic effects of persistent endocrine disrupters in marine mammals and birds. Mar Pollut Bull 45: 69-77.

Tavoni SK, Champagne CD, Houser DS, Crocker DE (2013) Lactate flux and gluconeogenesis in fasting, weaned northern elephant seals (Mirounga angustirostris). J Comp Physiol - B Biochem Syst Environ Physiol 183: 537-546.

Thompson FK (2007) Is There A Thyroid-Cortisol-Depression Axis? Thyroid Sci 2: 1-2.

Thomson CA, Geraci JR (1986) Cortisol, aldosterone, and leucocytes in the stress response bottlenose dolphins, Tursiops truncatus. Canadaian J Fish Aquat Sci 43: 1010-1016.

Tilbrook AJ, Turner Al, Clarke IJ (2000) Effects of stress on reproduction in non-rodent mammals: the role of glucocorticoids and sex differences. Rev Reprod 5: 105-113.

Veldhuis JD, Roelfsema F, Iranmanesh A, Carroll BJ, Keenan DM, Pincus SM (2009) Basal, pulsatile, entropic (patterned), and spiky (staccato-like) properties of ACTH secretion: impact of age, gender, and body mass index. J Clin Endocrinol Metab 94: 4045-52.

Walker BG, Boersma PD, Wingfield JC (2005) Field Endocrinology and Conservation Biology. Integr Comp Biol 45: 12-18.

Watanabe Y, Baranov E a., Sato K, Naito Y, Miyazaki N (2004) Foraging tactics of Baikal seals differ between day and night. Mar Ecol Prog Ser 279: 283-289.

Wikelski M, Cooke SJ (2006) Conservation physiology. Trends Ecol Evol 21: 38-46.

Zoeller RT, Tan SW, Tyl RW (2007) General background on the hypothalamic-pituitarythyroid (HPT) axis. Crit Rev Toxicol 37: 11-53. 